\title{
Recruiting and Retaining Participants in Citizen Science: What Can Be Learned from the Volunteering Literature?
}

\author{
Sarah West and Rachel Pateman
}

\begin{abstract}
New citizen science projects are emerging all the time as scientists, policy-makers, and non-governmental organisations see the value of conducting research in this way. Understanding what factors influence people to take part in citizen science projects and why participants continue their involvement are important questions for the field. Here, we bring together key theories from the volunteering literature with examples from the environmental volunteering and citizen science literature to describe the factors that influence people to start and continue participating in citizen science projects. Good project organisation is key, and project organisers need to consider potential participants' motivations; their personal attributes, circumstances and demographics; and how they will become aware of the opportunity. We discuss each of these factors with reference to both the academic and the grey (non-academic) literature, and based on this make general recommendations for those designing and running citizen science projects.
\end{abstract}

Keywords: volunteering; motivations; participants

\section{Introduction}

Citizen science is the partnering of scientists with volunteers to answer scientific questions (Dickinson et al. 2012). Volunteers can be involved in a number of aspects of citizen science projects, including designing projects and suggesting hypotheses; collecting, sorting, and analysing data; and communicating findings. Recruiting volunteers, or participants, is therefore integral to the success of citizen science projects, and low levels of recruitment or declines in participation could lead to projects ceasing (Morais et al. 2013). However, very little has been published in the academic literature about the factors that influence people to take part in citizen science projects and why participants continue their involvement, or not. This is a significant gap in our understanding because a) knowledge of what encourages participation is crucial for ensuring that opportunities are attractive to participants, and b) fulfilling people's motivations for participation can encourage prolonged engagement (Measham and Barnett 2007). Understanding people's motivations may also be useful for predicting the quality and quantity of participation (see Nov et al. 2014). As the number of citizen science projects continues to grow rapidly (Bonney et al. 2014), it is essential that project designers consider factors influencing participation to attract and retain participants.

Outside of citizen science, the research base around recruiting and retaining volunteers is relatively large, and we draw on this literature here because we believe that

Stockholm Environment Institute, University of York, GB

Corresponding author: Sarah West (sarah.west@york.ac.uk) useful lessons can be learned from this more established field. The volunteering literature is particularly relevant to citizen science as many organisations have recently rebranded volunteering opportunities as citizen science activities (Roy et al. 2012). Volunteering can be defined as planned, unpaid, pro-social behaviour that benefits strangers (Penner 2002). In citizen science, people also contribute their time without financial reward, and often the research being conducted does not have direct impact on the participants and is led by scientists whom the participants will never meet. Like volunteering, which spans long-term activities to micro-volunteering, done in short and discrete periods of time (Jochum and Paylor 2013), citizen science projects ask for participation from a few minutes up to participation over many years. Edwards (2014) also draws on the volunteering literature to discuss citizen science. He notes that although neither citizen science nor volunteering are clearly defined, the key characteristics of both are that participants are "unpaid, acting on free will, and acting to benefit others" (p. 138).

Volunteering plays a significant role in society across a broad range of sectors, including health and social care, sports, and the environment. Surveys have shown that in England $74 \%$ of respondents volunteered at least once in 2013-14 (Cabinet Office 2014), whilst in Canada this figure is $47 \%^{2}$ (Statistics Canada 2012). While the proportion of the population volunteering varies between nations, arguably correlated with the size of non-profit sectors in these countries (Salamon and Sokolowski 2001), clearly a vast number of people are engaging in volunteering in many different contexts. Furthermore, volunteering appears to be increasing (Cabinet Office 2014), 
perhaps because of the widening gap between needs and available funding (Asah and Blahna 2012) and the capacity of professionals to deliver work (Bell et al. 2008) such as monitoring the environment to meet government obligations (Mackechnie et al. 2011). As volunteering is playing an increasingly important role in society, considerable research has been conducted into understanding why people start and continue volunteering (Grimm and Needham 2012, Peachey et al. 2014, Lai et al. 2013). In this paper, we draw on this body of work about volunteering in general, complemented by studies of environmental volunteering and biological recording, to make recommendations for those designing and running citizen science projects. We have also drawn on the relatively limited literature that exists relating specifically to citizen science participants.

Citizen science projects can be categorised as "contributory," "collaborative," and "co-created" by the stages of the scientific process in which participants are involved and their degree of participation (Bonney et al. 2009). Contributory projects are those where scientists design the questions and the public helps to collect data. In collaborative projects, the public may also help to modify the questions, analyse data, and disseminate findings, whilst in co-created projects the public can be involved in all stages of the scientific process (Bonney et al. 2009). Whilst conducting this review, the vast majority of projects we encountered were contributory, but we believe that many of the lessons learned will be useful for anyone designing citizen science projects, regardless of type, as all projects need volunteers. Although our personal experience of citizen science is mainly with environmental projects, our literature search incorporated volunteering and citizen science in general, so we hope that some of these recommendations will be useful to other citizen science fields such as astronomy and public health.

To conduct this review, we used Web of Science with combinations of the terms "volunteer*," "environmental monitoring," "motivations," and "citizen science." We then read each abstract to determine whether it provided useful insight into why people begin and continue participating in citizen science projects. These terms allowed us to find academic papers on volunteering in general as well as the more limited papers on citizen science. Grey (non-academic) literature on volunteering was found by searching online using terms related to best practice in environmental volunteering, specifically "volunteer motivations," "volunteer policy," "volunteer recruitment," "volunteer experience," and "volunteer evaluation." This allowed us to find project reports and documents produced by the voluntary sector. In some cases, the grey literature found is based on findings from empirical research, and in other cases it is based on anecdotal evidence from project organisers. Using these search terms allowed us to draw on information from a range of academic disciplines (computer science, environmental science, psychology, environmental education, sociology) as well as information from the voluntary sector in order to shed light on the citizen science field. Based on this literature we make recommendations for those designing and running citizen science projects.

\section{Influences on participation}

Following Penner (2002), we see different stages of a volunteer's participation in a project: The decision to participate, initial participation, and sustained participation. Our review of the literature revealed several key factors that influence people's decisions to participate and to continue participating: According to Penner (2002), the desire to volunteer is a combination of dispositional variables (attributes of individuals) and organisational variables (attributes of the organisation running the project), and Hobbs and White (2012) found that the three main factors influencing people's decision to participate in biological recording schemes were 1) that they need to be aware the opportunity exists, 2) the opportunity needs to be appropriate for them, and 3) they need to be motivated. In this paper we discuss how project organisers can influence these factors. Often there is only a short period of time between the decision to participate and beginning to participate, so we consider these stages together in our discussion, although we do recognise that often people register to take part but do not move on to initial participation. For example, the European project Evolution MegaLab had more than 6000 registrations, but only $38 \%$ of them submitted data (Worthington et al. 2012).

A visual representation of these stages is shown in Figure 1, along with a checklist of things we recommend that project organisers consider to maximise the participant experience. In the rest of the paper we discuss the literature behind these recommendations.

\section{Initial participation}

In this section, we cover the key literature around three main topics in relation to participants that project organisers need to consider when designing their project: The motivations of potential participants, their personal circumstances and demographics, and how they will become aware of the project. This is important because once potential participants have heard about an opportunity, learned that it is accessible to them, and are motivated to take part, they can begin participating (Hobbs and White 2012).

\section{Motivations}

Individuals need to be motivated to participate in projects. Here we present some studies that have categorised what motivates volunteers (see Box $\mathbf{1}$ for a summary). We begin with two drawn from the general volunteering literature before moving on to discuss studies of environmental volunteers and citizen science participants which have explored these issues.

Finkelstien (2009) recognises intrinsic and extrinsic motivations of volunteers. Intrinsic motivations describe the desire to volunteer because volunteering is in some way inherently interesting or satisfying. In contrast, extrinsic motivations describe the willingness to volunteer because it leads to some other outcome, such as getting 


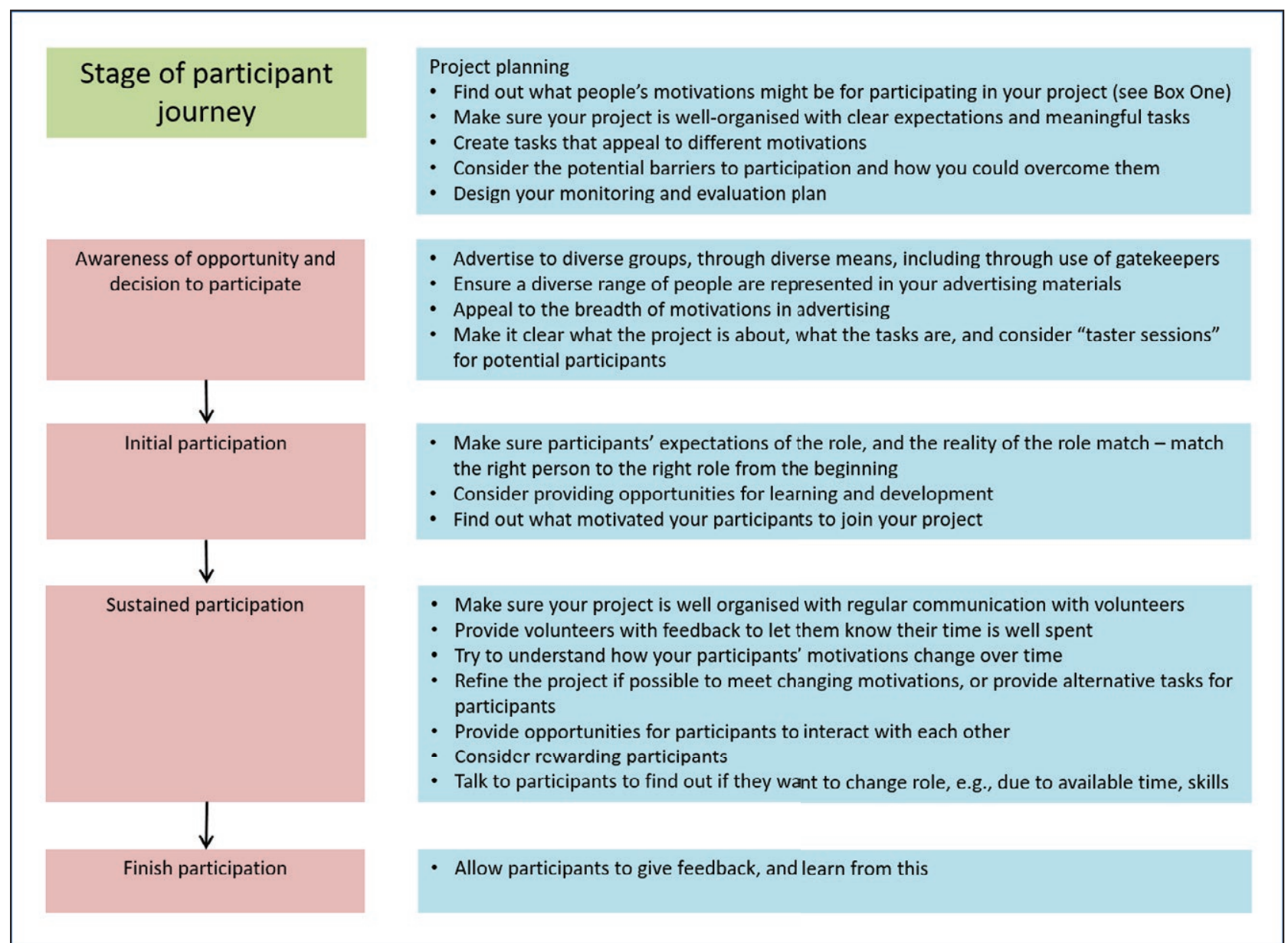

Figure 1: The journey that a participant takes when participating in a project (left side), with a checklist for project organisers corresponding to each of these stages (right side) to maximise the changes of people having a positive experience of participating.

Intrinsic Motivations (Finkelstien 2009)

- Understanding (Clary and Snyder 1999)

O Wanting to learn new things (Bell et al. 2008)

O Wanting to share existing knowledge with others (Bell et al. 2008)

- Values (Clary and Snyder)

o Helping other people (Raddick et al. 2013)

O Helping science (Raddick et al. 2013)

O Helping the environment (Hobbs and White 2012)

O Help a particular site (Jacobsen et al. 2012)

- Social (Clary and Snyder 1999)

- $\quad$ Enhancement (Clary and Snyder 1999)

- Protective (Clary and Snyder)

Extrinsic Motivations (Finkelstein 2009)

- $\quad$ Career (Clary and Snyder 1999)

Box 1: List of the motivations that may be held by citizen science volunteers. 
a new job (Finkelstien 2009). The functional approach to volunteering (Clary and Snyder 1999) is a theory that highlights the motivations that lead to individuals beginning and continuing volunteering. This approach has identified six motivations of volunteers:

- Understanding motivation where people want to learn new things.

- Values motivation where people have an altruistic concern for others.

- Social motivation where people are motivated by the desire to meet new people and because volunteering is a socially desirable thing to do.

- Enhancement motivation where people wish to improve themselves personally through volunteering.

- Protective motivation where people volunteer to reduce negative feelings or to address personal problems.

- Career motivation where people hope to gain experience that will benefit their future careers.

Career motivation would be classified as an extrinsic motivation, whilst the remainder are intrinsic motivations.

Some studies of environmental volunteers have built upon the motivations identified by Clary and Snyder (1999), for example Bruyere and Rappe (2007) and Jacobson et al. (2012). Other studies have developed their own categories that can be matched onto the Clary and Snyder categories, for example, Measham and Barnett (2007), Bell et al. (2008), Hobbs and White (2012), and Raddick et al. (2013). These studies have helped make Clary and Snyder's categories more relevant to environmental volunteering and citizen science. Values motivations can be divided into: Helping other people, helping science (see Raddick et al. 2013), and helping the environment (see Hobbs and White 2012). Bruyere and Rappe (2007), Measham and Barnett (2007), and Jacobson et al. (2012) identified an additional values motivation for environmental volunteers, which is that people who use a site (e.g., for recreation) often want to work in or improve the site. The "understanding motivation" can be divided into "wanting to learn new things" and "wanting to share existing knowledge with others" (see Bell et al. 2008). A summary of the motivations that may be held by citizen science volunteers can be seen in Box 1.

The importance that participants place on these different motivations varies among projects, and a few studies have examined this variation within environmental volunteering or citizen science projects. These studies showed that motivations of participants varied in terms of the motivations held and the relative importance that participants placed on them. For example, in the context of volunteers involved in an environmental programme in the USA, Van Den Berg et al. (2009) found all Clary and Snyder's motivations to be present except protective motivation. Hobbs and White (2012) asked participants in wildlife recording schemes in the UK why they got involved, and found that environmental (values) motivations were most prominent. Similarly, Bruyere and Rappe (2007), Jacobson et al. (2012), and Johnson et al. (2014) found environmental motivations, such as helping the environment, to be the most important motivations for participants involved in conservation projects. In their study of participants involved in the online Galaxy Zoo project, Raddick et al. (2013) also found the altruistic motivation of wanting to help science to be the most dominant. In contrast, Asah et al. (2014) found that socio-psychological (enhancement) motivations such as learning and career were mentioned nearly twenty times more often than environmental motivations, even though the volunteers were working on urban landscape restoration and conservation. This may be because the benefits of such work for the environment may not be obvious until months or years after the work (McDougle et al. 2011). The differing findings of these studies may also be explained by the differences in motivation categories used by the researchers. This highlights the need for more studies using existing frameworks to comparatively explore the link between project attributes and motivations of participants.

Volunteers are not a homogenous group of people. They can have a wide variety of motivations (Asah et al. 2014), and different people may engage in the same volunteering activity for different reasons (Clary and Snyder 1999). Furthermore, each participant can have multiple motivations, with most volunteers holding two or more key motivations (Clary and Snyder 1999, see also Bell et al. 2008, Asah et al. 2014). An individual's motivations can also change over time (Ryan et al. 2001). Career related motivations, for example, are particularly important earlier in people's lives (Clary and Snyder 1999, Jacobson et al. 2012), and younger people are often motivated by wanting to gain skills, whereas older volunteers are more likely to want to share their skills and give something back (Unell and Castle 2012).

When designing projects, project organisers may wish to create tasks that appeal to different motivations, although it should be noted that not all motivations will be catered for within each project (Bruyere and Rappe 2007).

\section{Personal attributes, circumstances, and demographics}

People may be motivated to volunteer, but for them to decide to participate in a specific project, the opportunity needs to fit in with the rest of their lives. Penner (2002) uses the term "dispositional variables" to refer to attributes of individuals which influence their likelihood of volunteering. These include personality traits, personal beliefs and values, and demographic characteristics such as age, income, and education. Potential participants have differing skill and experience levels, demographics, and amounts of time to offer, and some of these factors may present barriers to participation. It is important to note that barriers to participating in projects can be real or perceived (Unell and Castle 2012). For example, O'Brien et al. (2010) researched barriers to environmental volunteering and found time pressures to be one of the most important. Lack of time is an important perceived barrier for many people, who believe that volunteering requires more time than they have to give (Unell and Castle 2012), although it is possible to design tasks within projects which require only small time commitments. 
Some groups, such as low-income people, people with disabilities, and people of Black and Minority Ethnic origin (people of colour) are traditionally under-represented in environmental volunteering (Ockenden 2007). Underrepresentation is an important issue because environmental volunteering can improve social cohesion and can have health, social, and economic benefits (OPENspace 2003). If project staff have the aim of engaging under-represented groups, then the different barriers they may face to becoming involved need to be understood. Unemployed and low-income people tend to be under-represented in environmental monitoring schemes, particularly where there are financial implications for participation (Hobbs and White 2012). There is also a lack of ethnic diversity in environmental volunteers, at least in the UK (Ockenden 2007, 2008). This may be partly because some people from Black and Minority Ethnic groups feel that the UK countryside is a landscape inhabited by white people (OPENspace 2003). People with disabilities may also be under-represented; in a study in one region of the UK, $7 \%$ of environmental volunteers considered themselves to have a disability (Ockenden 2008), a figure considerably lower than the proportion of disabled people in the UK (Department for Work and Pensions 2012). An important barrier for less physically able people is the perception that volunteering always involves physical activity (Ockenden 2008).

In light of the under-representation of certain demographics within volunteering, project staff may want to consider how they can make opportunities appeal to different demographics and people with different skills and interests. For example, organisers may offer non-physical tasks to allow people who do not have the health to volunteer in more active roles to participate (O'Brien et al. 2010); or to offer expenses that may make volunteering more attractive to those on low incomes. Some people hold negative stereotypes of environmental volunteers to which they do not aspire (Ockenden 2008). As shown in the theory of homophily, social interactions are most likely to take place amongst people who share similar characteristics (Lin 2001), so seeing existing volunteers as people they identify with may make them more inclined to volunteer. For example, imagery of non-white people using the countryside may help to encourage people from minority ethnic groups to see the countryside as a place where all are welcome (Agyeman and Spooner 1997). It may be useful for project leaders to collect demographic information about their participants to see if there are sections of the local community that are not currently represented and tailor their recruitment materials accordingly.

\section{Awareness of opportunity}

For people to decide to participate, they need to be aware that the opportunity exists (Hobbs and White 2012). O'Brien et al. (2010) identify lack of information on opportunities for volunteering and a lack of understanding of what volunteering involves as key barriers to environmental volunteering. It is therefore vital to consider how potential participants will become aware of the opportunity. It is also important to continue to recruit participants throughout the project, as there may be a trend of decreasing participation over time (Sauermann and Franzoni 2014). Here our recommendations focus on how to attract a diverse range of people, which is particularly important if projects have educational as well as scientific goals.

Ockenden (2008) and Unell and Castle (2012) report that word-of-mouth is an effective way of recruiting new volunteers, with existing volunteers being particularly passionate advocates for the project (Russell 2009). Russell (2009) and McDougle et al. (2011) report that many people volunteer for more than one organisation, so projects could be promoted through other organisations. A disadvantage of recruiting via word-of-mouth is that it is likely to attract people who are already engaged in volunteering, who may not be particularly diverse (Ockenden 2007). Unell and Castle (2012) recommend that third party organisations ("gatekeepers") are used to broker volunteering opportunities. These include volunteering agencies and educational establishments, and they can be particularly good for recruiting young people, Black and Minority Ethnic people, and unemployed volunteers (Unell and Castle 2012). Identifying community leaders in different groups and enlisting their support in promoting the project can be critical. In these cases, it is important to create an environment of trust and support that overcomes known barriers (Natural England, undated). In contrast, a "scattergun approach" can be used to advertise opportunities to large numbers of people. This could include the use of press releases (to get newspaper, television, and radio coverage), social media and posters or leaflets in key locations (libraries, post-offices, faith-buildings, visitor centres and visitor attractions) (see Van Vliet et al. 2014 for a discussion of promotion methods within the Dutch phenology network Nature's Calendar). Matching messaging about volunteering opportunities to people's motivations has been shown to increase people's intentions to volunteer (Clary and Snyder 1999), and appealing to a range of motivations in publicity material may increase the number (and diversity) of people who want to participate in citizen science projects. Vignettes (little stories) profiling the motivations of diverse volunteers can be useful for recruitment (Van Den Berg et al. 2009). Publicity material should highlight the diverse benefits that participating in the project may achieve, in order to attract people with different motivations for volunteering (Grese et al. 2000).

The other key barrier to participation identified by O'Brien et al. (2010) is a lack of understanding of what volunteering involves. "Taster sessions" that allow individuals to try tasks may help to recruit participants (Natural England, undated). When advertising projects, we recommend making it clear what participating in the project involves, including the time commitment, nature of the activities, and whether any particular skills or abilities are required.

\section{Sustained participation}

Penner (2002) highlights the importance of both organisational and dispositional variables for sustaining volunteers beyond their initial participation. Good project 
organisation is key: Volunteers commonly report that poor organisation and feeling undervalued or overburdened are key reasons for dropping out of volunteering (Ryan et al. 2001, Locke et al. 2003), whereas volunteers are motivated to participate in projects that are well-organised with good leadership, clear expectations, and meaningful tasks (Jacobson et al. 2012). Volunteers' "job satisfaction" has been shown to predict their intention to continue (Wu et al. 2015), and here we discuss some things that project organisers can do to keep their volunteers satisfied.

\section{Motivations}

Participants in volunteering programmes "are not free labour, but individuals who will keep coming if their needs are fulfilled" (Ryan et al. 2001: 645), so as well as understanding what motivates people to begin participating, it is vital to understand what motivates them to continue (Measham and Barnett 2007). Failure to fulfill these motivations can lead to high turnover rates of volunteers, which can be time consuming and costly to a project if participants have to be repeatedly recruited and trained. However, although considerable research has been conducted regarding what triggers people to volunteer, less research has been done on the experience of volunteers once they are in place (Wilson 2012). What is known is that if volunteers feel their initial motivations are fulfilled, they are more likely to continue volunteering (Peachey et al. 2014). The "matching hypothesis" states that individuals sustain their involvement if their motivations match the opportunities provided by the project (Clary and Snyder 1999). Mismatches between participants' expectations and the objectives of project staff or reality of the role can lead to high turnovers of volunteers (Measham and Barnett 2007), so it is better to match the right person to the right role from the beginning (Ryan et al. 2001).

Interestingly, motivations for initial involvement have been shown to be a factor in longevity of involvement (Newton et al. 2014), with people with certain motivations more likely to continue volunteering than others. For example, McDougle et al. (2011) found that young people who were motivated to volunteer for social reasons were more likely to invest greater amounts of time in volunteering, compared to those who were motivated to learn new things or new skills. Motivations of volunteers can, however, change over time. Ryan et al. (2001) studied the motivations of long-term environmental volunteers and found that for new volunteers, a desire to help the environment and learn new things were important motivators, but social factors were significant in retaining volunteers in the long-term (Ryan et al. 2001). Project organisers should, therefore, incorporate research to understand changing motivations into the design of projects and use results to refine projects or tailor the experience of individual volunteers. Research suggests that participants may have a greater number of and different motivations to those that the project manager has identified (Grimm and Needham 2012), and may gain different benefits from participating than those expected by the project organisers (West 2015). For example, Bushway et al. (2011) summarise some of the benefits that older people may gain from environmental volunteering and suggest that the benefits to the individual (such as health, cognitive, and psychological benefits) may be greater than the benefits to the project. It may be beneficial, therefore, for project staff to research the motivations of their participants. This could be through conducting formal research or explicitly asking participants when they commence volunteering.

Providing feedback on how citizen science-collected data is being used is likely to be an important motivator for many participants (Singh et al. 2014). Volunteers want to feel that their time is well spent (Bruyere and Rappe 2007), therefore the impacts of participants' work should be monitored and communicated back to them (Van Den Berg et al. 2009, Unell and Castle 2012). Communication with participants could be done through a regular newsletter, which could include research findings, show what the data are used for, introduce any new staff or participants, and list training opportunities. Such communications can also be used to help recruit new participants. Newsletters and websites are commonly used, as are forums and social media (particularly Facebook and Twitter) (Natural England, undated), which can also be useful for providing a sense of community (Bell et al. 2008) and for answering queries (Morais et al. 2013) for projects in which participants work alone. A number of studies have highlighted the importance of providing opportunities for participants to interact with each other (Locke et al. 2003, Van Den Berg et al. 2009, Jacobson et al. 2012, Asah et al. 2014) to encourage sustained participation, so projects should consider providing such opportunities, even if only online. Opportunities should also be provided for participants to give feedback, for example, about project organisation issues (Unell and Castle 2012). Opportunities for feedback in general have been shown to be important for volunteer retention (Garner and Garner 2011).

Rewarding project participants is another way of motivating them to continue their involvement by showing them they are valued, although the research evidence on this is sparse (Locke et al. 2003). From their study of environmental volunteering in the UK, O'Brien et al. (2010) suggest several ways of motivating and rewarding people, including thanking people (verbally, or through newsletters, award schemes, and social events) and providing incentives such as long service badges or volunteer discount cards for stores or cafés. Some participants may appreciate being involved in decision making relating to the project or organisation. Accreditation, where participants receive formal recognition of the work they do, can be mutually beneficial: For participants it can provide evidence of increasing their skills and personal development, and for the organisation, accreditation can help to attract and retain more effective and skilled participants (Volunteering England 2009). However, accreditation creates extra administrative burden on the organisation and may deter some participants if they associate accreditation with formal or written examinations, or if it is overly bureaucratic, as some volunteers are put off by this (Ockenden 2008). One study found that more than one quarter of UK volunteers felt there was too much 
bureaucracy in their organisation and 17\% thought volunteering was becoming too much like paid work (Machin and Paine 2008). Some volunteers may be motivated to stay in the role because of learning and development opportunities (Newton et al. 2014), whilst others may not want "to be developed" (Locke et al. 2003: 94). A "one size fits all" approach to training and support does not work because it does not draw on individuals' strengths and motivations, i.e., different volunteers will require different levels and methods of support, and the support given needs to be tailored to the individual (Natural England, undated).

Personal attributes, circumstances, and demographics Locke et al. (2003) reviewed the volunteer retention literature, most of which comprises small-scale studies of volunteers in a diverse range of settings, and divided the factors affecting sustained volunteering into "personal factors and life events" and "organisations and context," echoing Penner's categories of dispositional variables and organisational variables (Penner 2002). Personal factors contributing to sustained volunteering included stability or continuity in personal life and, particularly importantly, previous experience of volunteering. In addition, anecdotal evidence suggests that personality and attitudes, faith, and demographic factors may play a role in sustaining volunteering, although this is less clear (Locke et al. 2003).

Penner's model of "sustained volunteerism" (2002) highlights the factors influencing an individual's decision to continue volunteering. This model emphasises the importance of "Volunteer Role Identity" for sustained volunteering. This is the extent to which an individual identifies with their role as a volunteer, and this becomes part of their self-concept. We have not discussed this here because the importance of this factor has not been clearly demonstrated in either the general volunteering or the environmental volunteering literature (although see Lu and Schuett 2014 for a discussion of the role of the related concept of "enduring involvement" in volunteers in outdoor leisure organisations). The impact of personal circumstances and demographics on sustaining participation in environmental programmes also has not, to our knowledge, been researched, so further study in this area would be beneficial.

As changes in personal circumstances can affect an individual's ability or desire to continuing participating, project staff should think about offering a variety of roles and giving people the option to switch between them. As time constraints are often a barrier to participation (O'Brien et al. 2010), this could include providing roles which require small amounts of time commitment.

\section{Key recommendations for project organisers}

Figure 1 summarises the recommendations we have made throughout this paper based on the literature we have read. It contains a checklist of things that project organisers may want to consider to maximise the participant experience. It begins with identifying roles for volunteers and ends with providing an opportunity for feedback when the participant leaves the project. In between these stages, project staff need to advertise the opportunity, appeal to people's motivations to encourage them to become interested in the opportunity and start volunteering, and give people a positive volunteer experience in order to retain them.

Through all stages, monitoring and evaluation should be conducted to assess whether the aims of the project and the needs of the participants are being met, and a monitoring and evaluation plan should be developed as part of the initial project planning (see Figure 1). Monitoring involves collecting numerical data about the people involved in activities (for example, age, gender, ethnicity) and can be useful for seeing if there are any sectors of society not participating in the project. Evaluation involves a judgment about the worth of the project and how effective it has been, and it can inform the direction of the project (or future projects). Formative evaluation, which is conducted during the lifetime of the project (Patton 2002), and ongoing monitoring can be particularly useful for providing information on whether the strategies for recruiting and retaining participants are effective.

Projects are often evaluated against outcomes, i.e., changes that occur as a result of the programme (Easton 1996), and thinking about intended outcomes can be a useful first step when designing projects (Shirk et al. 2012). Once the intended outcomes have been decided upon, methods to evaluate whether they are being achieved can be designed (see Phillips et al. 2014 for assistance with this).

\section{Conclusions}

Despite the importance of understanding the factors that influence people's participation in citizen science and other environmental projects, relatively little research has been published about what influences people to start participating or what encourages them to continue their involvement. In this paper we have summarised the key literature on this important topic using the general volunteering literature and the more limited literature relating to environmental volunteering and citizen science, and made recommendations for those running citizen science projects about how to recruit and retain diverse participants. Although participants in citizen science projects are generally unpaid, there are always costs associated with their help (Franzoni and Sauermann 2014). Many of the activities critical to citizen science (coordination of research, communication with volunteers, data screening and checking, compilation) are costly, and we agree with Tulloch et al. (2013) that cost-benefit analysis should ideally be conducted before commencing citizen science projects.

Research into citizen science participants, particularly longitudinal research, is needed to explore what people gain from participation and whether the factors detailed here are applicable to different types of citizen science projects. Research into participants' motivations could use the existing frameworks (see Box 1) to allow comparison between projects. Further research into participants is particularly important given the ever-expanding number of citizen science projects, all requiring people to 
participate. Findings from such studies should be shared with citizen science practitioners in order to build the evidence base for other practitioners and researchers to draw on and to improve practice.

\section{Acknowledgements}

The authors would like to acknowledge the help of the reviewers and editors, in particular Heidi Ballard, for their comments that helped to substantially revise this paper. We would also like to acknowledge our collaborators at Moors for the Future Partnership's Community Science Project who were the inspiration for this work.

\section{Competing Interests}

The authors have no competing interests to declare.

\section{Notes}

${ }^{1}$ Data from a survey commissioned by the UK government of 5105 people representative of people aged $16+$ in England.

2 Data from the Canada Survey of Giving, Volunteering and Participation of a sample of 15482 Canadians aged $15+$.

\section{References}

Agyeman, J. and Spooner, P., 1997. Ethnicity and the rural environment. In: Cloke, P. and Little, J. (eds.), Contested Countryside Cultures. London, UK: Routledge, pp. 197-217.

Asah, S.T. and Blahna, D.J., 2012. Motivational functionalism and urban conservation stewardship: Implications for volunteer involvement. Conservation Letters, 5(6): 470-477. DOI: https://doi.org/10.1111/j.1755263X.2012.00263.x

Asah, S.T., Lenentine, M.M. and Blahna, D.J., 2014. Benefits of urban landscape eco-volunteerism: Mixed methods segmentation analysis and implications for volunteer retention. Landscape and Urban Planning, 123(March): 108-113. DOI: https://doi.org/10.1016/j.landurbplan. 2013.12.011

Bell, S., Marzano, M., Cent, J., Kobierska, H., Podjed, D., Vandzinskaite, D., Reinert, H., Armaitiene, A., Grodzińska-Jurczak, M. and Muršič, R., 2008. What counts? Volunteers and their organisations in the recording and monitoring of biodiversity. Biodiversity and Conservation, 17(14): 3443-3454. DOI: https:// doi.org/10.1007/s10531-008-9357-9

Bonney, R., Ballard, H., Jordan, R., McCallie, E., Phillips, T., Shirk, J. and Wilderman, C.C., 2009. Public participation in scientific research: Defining the field and assessing Its potential for informal science education. A CAISE Inquiry Group Report. Washington, DC: Center for Advancement of Informal Science Education (CAISE).

Bonney, R., Shirk, J.L., Phillips, T.B., Wiggins, A., Ballard, H.L., Miller-Rushing, A.J. and Parrish, J.K., 2014. Next steps for citizen science. Science, 343(6178): 1436-1437. DOI: https://doi.org/10.1126/science.1251554

Bruyere, B. and Rappe, S., 2007. Identifying the motivations of environmental volunteers. Journal of Environmental
Planning and Management, 50(4): 503-516. DOI: https:// doi.org/10.1080/09640560701402034

Bushway, L.J., Dickinson, J.L., Stedman, R.C., Wagenet, L.P. and Weinstein, D.A., 2011. Benefits, motivations, and barriers related to environmental volunteerism for older adults: Developing a research agenda. The International Journal of Aging and Human Development, 72(3): 189-206. DOI: https://doi.org/10.2190/ AG.72.3.b

Cabinet Office, 2014. Community Life Survey 2013 to 2014: Statistical analysis. Available at https://www. gov.uk/government/statistics/community-lifesurvey-2013-to-2014-statistical-analysis (Last accessed 21st August 2015).

Clary, E.G. and Snyder, M., 1999. The motivations to volunteer: Theoretical and practical considerations. Current Directions in Psychological Science, 8(5): 156-159. DOI: https://doi.org/10.1111/1467-8721. 00037

Department for Work and Pensions, 2012. Family Resources Survey 2010/11. Available at https://www.gov.uk/ government/statistics/family-resources-survey201011 (Last accessed 21st August 2015).

Dickinson, J.L., Shirk, J., Bonter, D., Bonney, R., Crain, R.L., Martin, J., Phillips, T.B., Purcell, K. and Shirk, J., 2012. The current state of citizen science as a tool for ecological research and public engagement. Frontiers in Ecology and the Environment, 10(6): 291-297. DOI: https://doi.org/10.1890/110236

Easton, P.A., 1996. Sharpening our tools. Improving evaluation in adult and nonformal education. UNESCO Institute for Education and German Foundation for International Development. Available at http://unesdoc.unesco.org/images/0010/001099/109960eo.pdf (Last accessed 21st August 2015).

Edwards, R., 2014. Citizen science and lifelong learning. Studies in the Education of Adults, 46(2): 132-144. DOI: https://doi.org/10.1080/02660830.2014.11661662

Finkelstien, M.A., 2009. Intrinsic vs. extrinsic motivational orientations and the volunteer process. Personality and Individual Differences, 46(5-6): 653-58. DOI: https:// doi.org/10.1016/j.paid.2009.01.010

Franzoni, C. and Sauermann, H., 2014. Crowd science: The organization of scientific research in open collaborative projects. Research Policy, 43(1): 1-20. DOI: https://doi.org/10.1016/j.respol.2013.07.005

Garner, J.T. and Garner, L.T., 2011. Volunteering an opinion: Organizational voice and volunteer retention in nonprofit organizations. Nonprofit and Voluntary Sector Quarterly, 40(5): 813-28. DOI: https://doi. org/10.1177/0899764010366181

Grese, R.E., Kaplan, R., Ryan, R.L. and Buxton, J., 2000. Psychological benefits of volunteering in stewardship programs. In: Gobster, P.H. and Hall, R.B. (eds.), 2000. Restoring Nature: Perspectives from the Social Sciences and Humanities, Washington DC: Island Press, pp. 265-280.

Grimm, K.E. and Needham, M.D., 2012. Moving beyond the 'I' in motivation: Attributes and perceptions 
of conservation volunteer tourists. Journal of Travel Research, 51(4): 488-501. DOI: https://doi. org/10.1177/0047287511418367

Hobbs, S.J. and White, P.C.L., 2012. Motivations and barriers in relation to community participation in biodiversity recording. Journal of Nature Conservation, 20(6): 364-373. DOI: https://doi.org/10.1016/j. jnc.2012.08.002

Jacobson, S.K., Carlton, J.S. and Monroe, M.C., 2012. Motivation and satisfaction of volunteers at a Florida natural resource agency. Journal of Park and Recreation Administration, 30(1): 51-67.

Jochum, V. and Paylor, J., 2013. New ways of giving time: Opportunities and challenges in micro-volunteering. A literature review. Institute for Volunteering Research, NCVO. Available at http://www.ivr.org.uk/images/ stories/NESTA_literature_review_final_0502131.pdf (Last accessed 21st August 2015).

Johnson, M.F., Hannah, C., Acton, L., Popovici, R., Karanth, K.K. and Weinthal, E., 2014. Network environmentalism: Citizen scientists as agents for environmental advocacy. Global Environmental Change, 29: 235-45. DOI: https://doi.org/10.1016/j.gloenvcha.2014.10.006

Lai, M.H.C., Ren, M.Y.W., Wu, A.M.S. and Hung, E.P.W., 2013. Motivation as mediator between national identity and intention to volunteer: National identity and volunteerism. Journal of Community \& Applied Social Psychology, 23(2): 128-42. DOI: https://doi.org/10.1002/ casp. 2108

Lin, N., 2001. Social capital: A theory of social structure and action, New York: Cambridge University Press. DOI: https://doi.org/10.1017/CBO9780511815447

Locke, M., Ellis, A. and Davis Smith, J., 2003. Hold on to what you've got: The volunteer retention literature. Voluntary Action, 5(3): 81-99.

Lu, J. and Schuett, M.A., 2014. Examining the relationship between motivation, enduring involvement and volunteer experience: The case of outdoor recreation voluntary associations. Leisure Sciences, 36(1): 68-87. DOI: https://doi.org/10.1080/01490400.2014. 860791

Machin, J. and Paine, A.E., 2008. Managing for success: Volunteers' views on their involvement and support. IVR Research Bulletin. London, UK: Institute for Volunteering Research.

Mackechnie, C., Maskell, L., Norton, L. and Roy, D., 2011. The role of "Big Society" in monitoring the state of the natural environment. Journal of Environmental Monitoring, 13(10): 2687-2691. DOI: https://doi. org/10.1039/c1em10615e

McDougle, L.M., Greenspan, I. and Handy, F., 2011. Generation green: Understanding the motivations and mechanisms influencing young adults' environmental volunteering: Understanding environmental volunteering. International Journal of Nonprofit and Voluntary Sector Marketing, 16(4): 325-341. DOI: https:// doi.org/10.1002/nvsm.431

Measham, T.G. and Barnett, G.B., 2007. Environmental volunteering: Motivations, modes and outcomes.
Australian Geographer, 39(4): 537-552. DOI: https:// doi.org/10.1080/00049180802419237

Morais, A.M.M., Raddick, J. and dos Santos, R.D.C., 2013. Visualization and characterization of users in a citizen science project. In: Proc SPIE 8758, Defense, Security and Sensing, Next Generation Analyst, Baltimore MD on 29 April 2013. DOI: https://doi. org/10.1117/12.2015888

Natural England, undated. Volunteering in nature: Access to nature early findings. Available at http://publications.naturalengland.org.uk/file/10696026 (Last accessed 21st August 2015).

Newton, C., Becker, K. and Bell, S., 2014. Learning and development opportunities as a tool for the retention of volunteers: A motivational perspective. Human Resource Management Journal, 24(4): 514-30. DOI: https://doi.org/10.1111/1748-8583.12040

Nov, O., Arazy, O. and Anderson, D., 2014. Scientists@ Home: What drives the quantity and quality of online citizen science participation? PLOS ONE, 9(4): e90375. DOI: https://doi.org/10.1371/journal. pone.0090375

O'Brien, L., Townsend, M. and Ebden, M. 2010. "Doing something positive": volunteers' experiences of the well-being benefits derived from practical conservation activities in nature. Voluntas, 21: 525-545. DOI: https://doi.org/10.1007/s11266-010-9149-1

Ockenden, N., 2007. Volunteering in the natural outdoors in the UK and Ireland: A literature review. London, UK: Institute for Volunteering Research.

Ockenden, N., 2008. Environmental volunteering in North East of England. London, UK: Institute of Volunteering Research.

OPENspace, 2003. Diversity review: Options for implementation, Final Report and Research Note for the Countryside Agency. Available at http://www.openspace. eca.ac.uk/researchprojects_diversityreviewoptions. php (Last accessed 21st August 2015).

Patton, M.Q., 2002. Qualitative research and evaluation methods (3rd ed.). Thousand Oaks, CA: Sage Publications.

Peachey, J.W., Lyras, A., Cohen, C., Bruening, J.E. and Cunningham, G.B., 2014. Exploring the motives and retention factors of sport-for-development volunteers. Nonprofit and Voluntary Sector Quarterly, 43(6): 1052-1069. DOI: https://doi.org/ $10.1177 / 0899764013501579$

Penner, L.A., 2002. Dispositional and organizational influences on sustained volunteerism: An interactionist perspective. Journal of Social Issues, 58(3): 447-67. DOI: https://doi.org/10.1111/1540-4560.00270

Phillips, T.B., Ferguson, M., Minarchek, M., Porticella, N. and Bonney, R., 2014. User's guide for evaluating learning outcomes in citizen science. Ithaca, NY: Cornell Lab of Ornithology. Available at http://www.birds.cornell.edu/citscitoolkit/evaluation/ (Last accessed 21 ${ }^{\text {st }}$ August 2015).

Raddick, M.J., Bracey, G., Gay, P.L., Lintott, C.J., Murray, P., Schawinski, K., Szalay, A.S. and Vandenberg, J., 2013. 
Galaxy Zoo: Motivations of citizen scientists. ArXiv E-Prints. Available at: http://arxiv.org/abs/1303.6886.

Roy, H.E., Pocock, M.J.O., Preston, C.D., Roy, D.B., Savage, J., Tweddle, J.C. and Robinson, L.D., 2012. Understanding Citizen Science and Environmental Monitoring. Final Report on behalf of UK Environmental Observation Framework.UKEnvironmental Observation Framework. Availableathttps://www.ceh.ac.uk/sites/default/files/ citizensciencereview.pdf (Last accessed 5th February 2015).

Russell, J., 2009. "Making volunteering easier": The story of environmental volunteering in South West England. London, UK: Institute for Volunteering Research.

Ryan, R.L., Kaplan, R. and Grese, R.E., 2001. Predicting volunteer commitment in environmental stewardship programmes. Journal of Environmental Planning and Management, 44(5): 629-648. DOI: https://doi. org/10.1080/09640560120079948

Salamon, L.M. and Sokolowski, W., 2001. Volunteering in cross-national perspective: Evidence from 24 countries. Working Papers of the Johns Hopkins Comparative Nonprofit Sector Project, no. 40. Baltimore, MD: The Johns Hopkins Center for Civil Society Studies.

Sauermann, H. and Franzoni, C., 2014. Crowd science user contribution patterns and their implications. Proceedings of the NationalAcademyofSciences, 112(3):679-84. DOI: https://doi.org/10.1073/pnas.1408907112

Shirk, J.L., Ballard, H.L., Wilderman, C.C., Phillips, T., Wiggins, A., Jordan, R., McCallie, E., Minarchek, M., Lewenstein, B.V., Krasny, M. and Bonney, R., 2012. Public participation in scientific research: A framework for deliberate design. Ecology and Society, 17(2): 29. DOI: https://doi.org/10.5751/ES-04705-170229

Singh, N.J., Danell, K., Edenius, L. and Ericsson, G., 2014. Tackling the motivation to monitor: Success and sustainability of a participatory monitoring program. Ecology and Society, 19(4): 7. DOI: https://doi.org/ 10.5751/ES-06665-190407

Statistics Canada, 2012. Volunteering in Canada. Available at http://www.statcan.gc.ca/pub/11-008-x/2012001/ article/11638-eng.pdf (Last accessed 20 ${ }^{\text {th }}$ July 2016).
Tulloch, A.I.T., Mustin, K., Possingham, H.P., Szabo, J.K. and Wilson, K.A., 2013. To boldly go where no volunteer has gone before: Predicting volunteer activity to prioritize surveys at the landscape scale. Diversity and Distributions, 19(4): 465-480. DOI: https://doi.org/ $10.1111 / \mathrm{j} .1472-4642.2012 .00947$

Unell, J. and Castle, R., 2012. Developing sustainable volunteering within the Natural Connections Demonstration Project: A review of evidence. Natural England Commissioned Report NECR096. Available at publications.naturalengland.org.uk/file/1995537 (Last accessed $21^{\text {st }}$ August 2015).

Van Den Berg, H.A., Dann, S.L. and Dirkx, J.M., 2009. Motivations of adults for non-formal conservation education and volunteerism: Implications for programming. Applied Environmental Education \& Communication, 8(1): 6-17. DOI: https://doi. org/10.1080/15330150902847328

Van Vliet, A.J.H., Bron, W.A. and Mulder, S., 2014. The how and why of societal publications for citizen science projects and scientists. International Journal of Biometeorology, 58(4): 565-77. DOI: https://doi. org/10.1007/s00484-014-0821-9

West, S.E., 2015. Understanding participant and practitioner outcomes of environmental education. Environmental Education Research, 21(1): 45-60. DOI: https://doi.org/10.1080/13504622.2013.879695

Wilson, J., 2012. Volunteerism research: A review essay. Nonprofit and Voluntary Sector Quarterly, 41(2): 176-212. DOI: https://doi.org/10.1177/0899764011434558

Worthington, J.P., Silvertown, J., Cook, L., Cameron, R., Dodd, M., Greenwood, R.M., McConway, K. and Skelton, P., 2012. Evolution MegaLab: A case study in citizen science methods. Methods in Ecology and Evolution, 3: 303-309. DOI: https://doi.org/10.1111/ j.2041-210X.2011.00164.X

Wu, Y., Li, C. and Khoo, S., 2015. Predicting future volunteering intentions through a self-determination theory perspective. VOLUNTAS: International Journal of Voluntary and Nonprofit Organizations. DOI: https:// doi.org/10.1007/s11266-015-9570-6

\begin{abstract}
How to cite this article: West, S and Pateman, R 2016 Recruiting and Retaining Participants in Citizen Science: What Can Be Learned from the Volunteering Literature? Citizen Science: Theory and Practice, 1(2): 15, pp.1-10, DOI: https://doi.org/10.5334/ cstp.8
\end{abstract}

\title{
Submitted: 16 March 2015 Accepted: 24 August 2016 Published: 31 December 2016
}

Copyright: (c) 2016 The Author(s). This is an open-access article distributed under the terms of the Creative Commons Attribution 4.0 International License (CC-BY 4.0), which permits unrestricted use, distribution, and reproduction in any medium, provided the original author and source are credited. See https://creativecommons.org/licenses/by/4.0/. 